\title{
O eletrencefalograma em criminologia *.
}

\author{
Odon Ramos Maranhão \\ Professor livre-docente de Medicina Legal na \\ Faculdade de Direito da Universidade de \\ São Paulo.
}

\begin{abstract}
Resumo: I Generalidades. II Conceito. III Aparelho e técnica. IV Ritmos cerebrais. V Variaçôes fisiológicas. VI Fatôres psicológicos. VII Ritmos anormais. VIII Principais anomalias. IX Valor do E.E.G. X O E.E.G. em criminologia. XI Resultados de 1.000 traçados de reclusos de São Paulo. XII Conclusôes. XIII Notas Bibliograficas.
\end{abstract}

\section{Generalidades.}

$E$ do conhecimento geral que os tecidos possuem propriedades elétricas. Referências aos registros gráficos dos potenciais elétricos colhidos de várias regiões corpóreas são relativamente freqüentes em conversas de leigos. Assim se ouve de alguém que apresenta anomalias do eletrocardiograma; de outrem que se submeteu a provas eletromiográficas; de um terceiro que vai ser examinado pela eletrencefalografia. Realmente são bem conhecidas as experiências de se estimular eletricamente um nervo para se obter uma contração muscular e qualquer estudante de fisiologia já teve o ensejo de medir a velocidade dos impulsos nervosos ou calcular o limiar de excitabilidade de um músculo. Já em 1875 Catton evidenciava a presença de corrente elétrica na corticalidade cerebral. Entretanto, somente em 1924 Hans Berger pôde

* Capítulo do trabalho Estudos de Criminologia - premio "Oscar Freire" de Criminologia 1970. O autor foi, anteriormente, psiquiatra do manicômio Judiciário e do Instituto de Biotipologia Criminal e Professor de psicopatologia no Instituto de Psicologia da U.S.P. 
obter um eletrencefalograma humano. A partir de 1935, quando Lennox, Gibbs e Gibbs publicaram os primeiros achados eletrencefalográficos em epiléticos humanos, os conceitos sobre as correlações clínicas e eletrencefalográficas tem evoluído muito. Tais conhecimentos constituem hoje uma especialidade e definem um campo científico bem caracterizado, com doutrina, técnica e método particular.

\section{Conceito.}

Entendemos por eletrencefalograma e designamos pela sigla E. E. G. o traçado contínuo das variações do potencial elétrico cerebral, obtido por aparelho próprio - eletrencefalógrafo - a partir da pele intacta do crânio. O aparelho colhe potenciais bio-elétricos baixíssimos, os amplifica e transfere a penas inscritoras e estas promovem o registro contínuo em fita de papel. É evidente que não se trata do registro da corrente elétrica de uma determinada célula nervosa, mas a resultante da somação de milhares de células de uma dada região cerebral. E de se ponderar, igualmente, que inúmeros fatores modificam ou interferem no registro: a presença da neurologia, de vasos sangüíneos, do líquido cefaloraquidiano, da camada óssea, etc.. Para termos uma idéia do que está ocorrendo no encéfalo como um todo, é necessário que tomemos traçados de várias áreas cerebrais. Os aparelhos geralmente dispõem de oito canais de registro, o que possibilita um exame de quatro áreas à direita e de quatro à esquerda. Entretanto, existem eletrencefalógrafos com 16 canais e até com maior número. O registro além de contínuo é simultâneo em todos os canais, para poder possibilitar um estudo de conjunto. Eventualmente, para fins de pesquisas, pode-se fazer o traçado conjunto do eletrocardiograma e outros (traçados poligráficos).

\section{Aparelho e técnica.}

Uma vez sabido que os potenciais elétricos cerebrais são 
excessivamente baixos, torna-se evidente que o estudo só é possível através de um registro em que estes potenciais sejam convenientemente ampliados. Por isso o fundamento dos aparelhos eletrencefalográficos é bastante simples. Trata-se de um sistema de válvulas eletrônicas amplificadoras, em conexão com um sistema de inscrição oscilográfica, usando-se tinta comum e papel adequado. Cada conjunto de um sistema amplificador e de um sistema inscritor, constitui o que se denomina um "canal" E cada canal explora uma determinada região cerebral, conforme aqui já se fêz menção. As variações de potenciais eletrocerebrais são colhidas na superfície do couro cabeludo por condutores especiais denominados electrodos. Cada electrodo é constituído de uma pequena placa de metal, de 5 a $10 \mathrm{~mm}$ de diâmetro, com superfície plana ou ligeiramente côncava. O material empregado é bastante variado. Este electrodo está ligado a um fio, bastante flexível, bastante fino, que é coberto de camada isolante e liga-se ao aparelho, num determinado canal. $O$ aparelho dispõe de um sistema de chaves seletoras para controlar o funcionamento de cada canal e assim selecionar qual o electrodo que está sendo usado num dado momento do exame. $\mathrm{Pa}$ ra que os electrodos apresentem boa aderência ao couro cabeludo empregam-se pastas adequadas. Estas são formadas de uma parte líquida volátil e uma parte consistente em que existem elementos metálicos. Segundo alguns não há necessidade de se recortar o cabelo; basta que os fios sejam repartidos e que a pasta seja convenientemente aplicada ao couro cabeludo. O paciente é colocado em decúbito dorsal, em posição confortável e mantido de olhos fechados. O ambiente deve ser isolado, do ponto de vista sonoro, e do ponto de vista elétrico. $O$ paciente deve ser mantido em repouso e completamente relaxado. Durante a tomada do traçado empregam-se várias técnicas, constituindo diferentes etapas do exame, conforme adiante se dará contas. O conjunto de electrodos selecionados para se obter um determinado traçado recebe o nome de programa. Essa seleção deve ter em vista a fi- 
nalidade do exame. Os cuidados todos acima referidos têm por finalidade evitar que existam interferências, as mais variadas possíveis, que produziriam artefatos no traçado a ser posteriormente estudado. Algumas características são fundamentais e exigíveis de qualquer aparelho para dar bom resultado na prática:

a) Cada canal deve ter características amplificadoras idênticas aos demais. Amplificação linear para todos os potenciais de 7 a 70 ciclos por segundo;

b) $\mathrm{O}$ aparelho deve produzir um registro permanente em fita de papel; mente;

c) As penas inscritoras devem funcionar sincrônica-

d) Deve haver possibilidade de calibração apurada em todos os canais;

e) Deve haver dispositivo para se introduzir no registro um sinal padrão de 5 microvolts para se testar a sensibilidade do aparelho.

Satisfeitos os requisitos técnicos, é possível, então, se obter um conveniente traçado.

\section{Rítmos Cerebrais.}

Nas pessoas adultas acordadas dois ritmos podem ser tidos como normais:

a) Rítmo Alfa - Esta atividade é encontrada nas duas regiões pós-centrais, nas cabeças dos adultos. O rítmo é simétrico nos dois lados. É maior em tamanho na cortex paristo-occipial e se apresenta com amplitude menor nas regiões anteriores, especialmente na área pré-frontal. A sequiência varia de 8 a 12 ciclos por segundo, com uma variação máxima de 1 ciclo por segundo, para cada indivíduo. Uma instabilidade que permite uma variação superior a $l$ ciclo por segun- 
do, num mesmo indivíduo, deve ser considerado um fenômeno anormal. A amplitude varia de 20 a 100 microvolts, mas essa variação tem pouco significado, pois estará altamente influenciada pela distância entre os electrodos. Quando se observa uma assimetria da amplitude constante deve-se considerar a situação como anormal, se persiste em mais de $50 \%$ do traçado. Tratando-se de pessoas jovens, um rítmo alfa mais largo pode ser encontrado na cortex do lado direito. En condições padrão, tomado o traçado com os olhos fechados, o rítmo alfa está presente de $5 \%$ a $100 \%$ do tempo na maior parte dos adultos acordados. A ausência do rítmo alfa não é obrigatoriamente um fenômeno anormal. A ausência pode ser abservada em $1 \%$ da população geral, sem sinais clínicamente anormais. Entretanto, uma diminuição do rítmo alfa, quando observada, sugere situação patológica. As pessoas tensas podem apresentar uma ligeira diminuição do rítimo alfa. Tal diminuição desaparece depois de alguns segundos de ser conservada com os olhos fechados, durante a hiperpnéia, a que se fará referência adiante. $O$ rítmo alfa parece ser produzido por células em percepção visual de cortex, em condições de repouso. A percepção visual, ou atividades mentais visuais, podem provocar uma parada do rítimo, o que se denomina "bloqueio do rítmo alfa" $\mathrm{O}$ bloqueio, quando aparece, deve ser observado bilateralmente.

b) Rítmo Beta - Êste rítmo não é observado em todos os indivíduos normais, por causa de uma ampla difusão do rítmo alfa que é mais amplo que o beta. Com o aumento de idade, o rítmo beta se torna progressivamente mais proeminente. Sua frequiência média é de 18 a 30 ciclos por segundo e sua amplitude bem menor: 10 a 30 microvolts. O rítmo é mais proeminente na proximidade da fissura central, de ambos os lados. A atividade beta pode ser ampliada pela ação de barbitúricos. Quando o rítmo beta está ausente de um lado, e bastante proeminente de outro, sugere a existência de uma lesão, no primeiro lado considerado. Os rítmos alfa e beta, são os únicos fenômenos observáveis nas pessoas adul- 
tas, acordadas. No E.E.G. da criança e no de adultos que estão sob sono, da mesma forma que em muitos processos patológicos que atingem o cérebro, rítmos mais lentos podem ser observados. Estes podem ser divididos em dois tipos: o tipo teta e o delta.

c) Rítmo Teta - Pode ser observado normalmente no E.E.G. de crianças novas, com menos de 10 anos de idade. Mas ao atingir 15 anos, a maior parte das crianças já não apresenta essa atividade que pode reaparecer nos adultos nos estados profundos de sono. A sua freqüência varia de 4 a 6 ciclos por segundo, com amplitude bastante variável; esta é mais ampla na criança e menor no adulto em estado de sono. $\mathrm{O}$ rítmo teta aparece preferentemente nas áreas parietais e temporais. A presença de rítmo teta, no adulto acordado, é encontrada numa porção de processos patológicos, mas como dado isolado, ocorre relacionado a lesões na proximidade do terceiro ventrículo. Rítmos teta, de variados graus, são encontrados na criança e nos adultos em cerca de $15 \%$ da população, como uma anomalia constitucional e encontrado numa proporção considerável de pessoas que sofrem de desordens neuro-psiquiátricas.

d) Rítmo Delta - A freqüência deste rítmo varia de meio em meio até 4 ciclos por segundo. A divisão de rítmos em teta e delta foi proposta na Inglaterra, por GraYwalter, $€$ tem sido geralmente aceita na Inglaterra e na Europa; mas nos Estados Unidos da América muitos autores se referem a rítmos inferiores a 8 ciclos por segundo, como rítmo delta. O ritmo delta ocorre somente na pessoa adulta em sono profundo. Nas crianças com menos de 3 anos, o rítmo delta é um achado freqüente no E.E.G. A presença de rítmo delta contínua e generalizada no adulto está associada seja com inconsciência ou com algum comprometimento desta. Nas condições em que pode aparecer inconsciência, o rítmo beta surge nas áreas frontais de cortex. A descarga local de 
rítmo delta em uma única área da cortex, indica comprometimento profundo mas reversível da função encefálica.

e) Fenômenos Transitórios - Ondas em espículas a espículas-ondas ("Sharp") São produzidas por descargas repentinas e sincrônicas de um grande número de células nervosas e podem ocorrer em qualquer área do sistema nervoso. Se os demais dados foram semelhantes, quanto mais ampla a onda, tanto maior o número das células comprometidas. Quanto maior a duração da onda "Sharp" tanto maior a distância entre as vias neuronais situadas entre o eléctrodo que a registra e a situação do foco da descarga elétrica. A localização de uma onda :Sharp" num determinado eléctrodo significa, portanto, que este está próximo, embora não exatamente sobre o foco que a produz. As ondas em espícula podem ocorrer de uma maneira difusa em qualquer parte da cortex de um epilético. A presença de rítmo delta, limitada a uma determinada área da cortex, sempre é indicativa de um comprometimento da função encefálica, de caráter severo, porém reversível.

\section{Variações fisiológicas.}

1 Idade - Observam-se muitas variações nos eletrencéfalogramas atribuíveis à idade. Os rítmos mudam através do tempo. $\mathrm{O}$ rítmo delta está presente na infância. $\mathrm{O}$ rítmo teta, persiste até a idade de dez anos, podendo contudo, persistir até aos 20 anos. $\mathrm{Na}$ realidade não se pode estabelecer com segurança qual a idade em que os rítmos teta desaparecem completamente. A presença de rítmos teta na pessoa de menos de vinte anos não deve ser levada em consideração. $\mathrm{Pa}$ rece estar influenciada por uma série de fatores fisiológicos, tais como a fadiga, a glicemia, a tensão de gás carbônico no sangue cerebral, o metabolismo hídrico e outros semelhantes. Assim, o aparecimento de pequenas ondas teta, nessas pessoas, não oferece valor diagnóstico, por não ter significado patológico. Nas fases mais avançadas de idade as ondas beta 
passam a se tornar proeminentes o que se observa geralmente depois dos cinqüienta anos.

2. Hereditariedade - As características básicas do E.E.G., tais como a freqüência de rítmo alfa, a sua distribuição, amplitude e resposta ao estímulo visual, da mesma forma que do rítmo beta, presente ou não, além da persistência ou não dos rítmos teta nas pessoas adultas, estão provavelmente determinados pela ação dos gens. A prova disto procede da observação de muitos pesquisadores, que demonstraram tais padrões serem muito semelhantes nos traçados de gêmeos idênticos, tanto nos limites da normalidade como fora dela. Estudado um par de gêmeos idênticos epiléticos e encontradas espículas no traçado, haverá $80 \%$ de probabilidade de que o outro irmão gêmeo também apresente tais alterações, ainda que clínicamente não se torne evidente a epilepsia. Os mesmos dados de correspondência foram estudados em grupos de irmãos com perturbações de comportamento, conduta anti-social ou epilepsia, que apresentavam em sua maioria E.E.G. anormal. Entretanto, a correspondência de traçados não é algo obrigatório. Há também grandes probabilidades de que nesta família os pais apresentam, ambos, alterações do eletrencefalograma.

3. Sexo - A atividade mais lenta, rítmo bats, está com muito mais probabilidade presente entre as mulheres que entre os homens, mas ainda se desconhece o significado deste achado.

4 Sono - Algumas alterações acontecem no traçado quando a pessoa começa a dormir. Por isto é muito importante que qualquer eletrencefalografista aprenda a reconhecer este fenomeno no E.E.G., pois ocorrerá muito comumente, quando o exame se torna mais demorado. As falhas em reconhecer o fenômeno de sono, que é bastante transitório, poderá levar o examinador a considerar um eletrencefalograma fora da normalidade quando não se trata do caso. 
5 Glicemia - As características do E.E.G. são bastante influenciáveis pela mudança do nível de açúcar sangüíneo. Isto é particularmente evidente nos jovens. Pequenas anomalias podem estar presentes no E.E.G. de um jovem, tais corno o aumento de um rítmo teta, quando a glicemia está abaixo de $80 \mathrm{~mm} \%$. No entanto se mostram ausentes quando se aumenta para $100 \mathrm{~mm} \%$. Existe neste particular uma grande variação de indivíduo a indivíduo. Trabalhos bem conduzidos por Davis e Hill demonstraram uma relação direta entre alterações do eletrencefalograma e o nível de açúcar sangüíneo. A hiperglicemia facilitou o aparecimento de ondas em espícula e espícula-onda com uma freqüência de 3 por segundo no caso de epiléticos e também dè alguns esquizofrênicos catatônicos. Há muitos fenômenos patológicos que podem na realidade ser observados com maior facilidade quando o nível de açúcar sangüíneo está mais baixo. Entretanto, tais alterações desaparecem quando o nível de açúcar sangüíneo é elevado aos padrões de normalidade.

6. Hiperpnéia - Tem sido usada como um teste clínico para facilitar o aparecimento de fenômenos epiléticos. Desde que se introduziu a eletrencefalografia na clínica, têm-se usado esta técnica como rotina no exame, para facilitar o aparecimento das alterações referidas. Quatro eventualidades ocorrem na prática:

1) produção de padrões epiléticos no E.E.G. usualmente onda de 3 ciclos por segundo e espículas.

2) o aumento da assimetria nos padrões normais, observados antes da hiperpnésia. Tal dado serve para esclarecer a lesão unilateral de um hemisfério encefálico;

3) um rítmo delta assimétrico - por exemplo em jovens com hipoglicemia, se nós prolongarmos a hiperpnéia por um período de três minutos, poderá aparecer onda delta bilateral. Havendo assimetria, esta resposta constitue evidência de uma lesão cerebral. 
4) o aparecimento de ondas delta bilaterais, de alta voltagem - neste caso, em se tratando de pessoas de menos de vinte anos, tal dado não terá grande importância, mas numa pessoa mais idosa, pensaremos numa instabilidade do E.E.G. à hiperpnéia, como indicativo de uma lesão cerebral antiga, embora não ofereça nenhuma severidade ou gravidade. Dennis Hill dá grande importância à influência da glicemia associada à hiperpnéia como fator para aparecerem alterações eletrencefalográficas, não conseguíveis de outra forma. Assim o diagnóstico de estabilidade e de instabilidade está até certo ponto influenciado pela escola considerada.

7 - Balanço hídrico - Quando grande quantidade de água é ingerida e retida pelo efeito da injeção de pitrecin apenas alterações muito discretas podem ocorrer em alguns indivíduos. Nessas condições pode ocorrer aumento da instabilidade dos rítmos corticais, em pessoas anormais, durante o exame com hiperpnéia. As observações de vários autores são favoráveis a esta interferência no eletrencefalograma.

\section{Fatores Psicológicos.}

a) Fatores temporários ou reversíveis - Quando o indivíduo está tranquiilo e relaxado, com os olhos fechados, a atividade alfa está presente, nos indivíduos adultos. Se entretanto a sua atenção for perturbada por estímulos visuais, sejam procedentes do ambiente externo, seja porque a pessoa está pensando com símbolos visuais, então a atividade alfa tende a desaparecer no E.E.G. O indivíduo que está tenso, mesmo com seus olhos fechados, apresenta uma lentificação do rítmo alfa. Se ele estiver apreensivo e ansioso, haverá pouca atividade alfa. Neste caso o rítmo beta, mais lento, começa a aparecer nas regiões centrais e se torna proeminente. Se o paciente se mostrar bastante abstraído e sonolento, então o E.E.g. tende a perder o seu rítmo alfa. Na medida em que 
a sonolência aumenta, ondas mais lentas vão aparecendo e o rítmo alfa é substituído pelo rítmo teta, na medida em que o indivíduo passe para o sono. Assim a alteração poderá se apresentar tanto no indivíduo excessivamente tenso como naquele que se encontra sonolento. Contudo, é perfeitamente possível fazer-se uma diferenciação. Se um determinado estímulo solicita uma pessoa que já está tensa, dará resultado diferente de quando ela se encontra sonolenta, pois neste segundo caso reaparece, em forma intempestiva, o rítmo alfa. Quando a consciência de alguma forma está comprometida, com excessão do transe hipnótico e das manifestações histéricas, as alterações do E.E.G., tendem a se voltar para uma onda lenta. Quando o indivíduo está inconsciente ondas muito lentas dominam em todas as áreas corticais. Isto é verdade menos nos casos de coma.

b) Fatores Permanentes - Os fenômenos eletrencefalográficos não parecem estar diretamente relacionados a um determinado fator psicológico com excessão dos comprometimentos da consciência. Não se conhece nenhum relacionamento por exemplo, com o quociente de inteligência, a menos que se trate de pessoa com Q.I. inferior a cinco anos, porque ai estamos diante de um caso de deficiência mental, na dependência de defeito cerebral evidente. Então a atividade alfa tenderá a se lentificar. Aspectos mais complexos da personalidade e do temperamento parecem não influenciar específicamente o E.E.g. Os estudos iniciais que pretenderam estabelecer determinadas relações neste campo não foram confirmados por investigações mais demoradas e mais profundas. Existem, contudo, dados interessantes no que se refere à análise de casos, como nas chamadas "personalidades psicopáticas" Enquanto se conhecem consideráveis variações individuais dos padrões do E.E.G. em pessoas normais, não se conseguiu ainda estabelecer conveniente e satisfatória relação aos diferentes fatores psicológicos que podem aparecer ern cada circunstância especial. 


\section{Rítmos anormais.}

O critério de anormalidade de um eletrencefalograma se baseia em modificações da amplitude, da simetria, distribuição e variação das freqüências, tendo sempre presente o fator idade que constitui um elemento importantíssimo na organização e na estabilidade do rítmo, assim como em sua configuração geral. As anormalidades podem ser divididas em contínuas e paroxísticas. As anormalidades contínuas podem ser difusas e locais. As anormalidades contínuas difusas se encontram nas lesões cerebrais inflamatórias e degenerativas. As anomalias contínuas e locais podem aparecer como seqüela das difusas contínuas. Podem aparecer também nos tumores, nos abcessos, nos hematomas sub-durais e em outros processos que comprometem o tecido nobre: nas cicatrizes meningo-cerebrais e nas aderências; nas hemorragias sub-aracnoideias; nas lesões vasculares; na esclerose em placas; como seqüela lobectomias pré-frontais e em certas psicoses funcionais. Lesões puramente destrutivas produzem menos sinais nos eletrencefalogramas do que os processos inflamatórios e irritativos. A atividade anormal no caso de lesões tumorais ou abcessos está determinada pelo tecido nervoso vizinho já que o tumor, qualquer que seja a massa estranha, é eletricamente inativo. Também deve-se ter em linha de conta que a localização se fará com dados tanto mais exatos quanto mais próximos estejam da superfície do encéfalo. Os tumores profundos, sub-corticais da linha média como da parte posterior à hipófise, podem oferecer poucos sinais de localização, com excessão daqueles que se acham na fossa posterior de crianças, onde se tem descrito anomalias contínuas, localizadas na região occipital. Um diagnóstico diferencial entre uma lesão focal causada por um tumor ou por uma lesão vascular pode se estabelecer tomando-se traçados repetidos do mesmo indivíduo com intervalos variados. Se se tratar de um tumor os sinais focais localizados irão aumentando ao contrário do que ocorre com lesão vascular. Os rítmos paroxísticos podem ser 
localizados e generalizados. Os rítmos paroxísticos generalizados caracterizam estados convulsivos, se bem que não sejam exclusivos dêles. As hipersincronias são alterações da amplitude sem modificação da freqüiência. Esses rítmos paroxísmicos generalisados podem ser de freqüência rápida como ocorre no grande mal, ou frequiências lentas, como na epilepsia psicomotora, e nas formas mixtas em que ondas lentas e rápidas se sucedem alternadamente, como se verifica no pequeno mal epilético, caracterizado por alternâncias rápidas e lentas de 3 ciclos por segundo simultâneamente registradas em todos os eléctrodos. Quando a freqüência se limita a descargas de 2 ciclos por segundo constitui o que se chama variante de pequeno mal. Rítmos paroxísticos generalizados também se observam depois do eletrochoque e sua persistência no fim do tratamento exige que todo exame psiquiátrico passe por uma investigação dêste acidente, porque em caso de ser êle ignorado poderá haver êrro diagnóstico eletrencefalográfico. Rítmos paroxísticos localizados observam-se especialmente nas epilepsias focais. Constituem um elemento de grande valor para o diagnóstico, e podem constituir o único sinal revelador de uma lesão epleptógena. Tem sido descrito também na psicose involutiva onde aparecem mais nas regiões anteriores e do vertx.

\section{Principais anomalias do E.E.G.}

Apresentamos agora em forma de resumo as principais alterações do E.E.G.

a) ondas lentas generalizadas - Aparecem nos processos cerebrais difusos, de origem traumática, vascular, infecciosa ou tóxica. Também estão presentes na epilepsia generalizada e nas afecções do tronco cerebral, de qualquer etiologia. Assinalam o caráter agudo do processo mórbido.

b) depressão local da atividade elétrica - Quando num traçado cujo conjunto está dentro dos limites da normalidade - aparece uma depressão da atividade elétrica de ca- 
ráter focal, estamos diante de um dado de grande valor na localização de uma lesão devida às mais variadas causas: destruição do parênquima, hematoma sub-dural, necrose cortical, atrofia.

c) focos de onda delta - Quando aparece atividade elétrica do tipo delta, com caráter focal bem definido, o significado é idêntico ao anterior. Os tecidos tumorais ou necrosados são elétricamente inativos e na sua proximidade aparecem ondas delta. Enquanto a depressão elétrica indica, em geral, lesão periférica, o foco de ondas delta se relaciona à lesão mais profunda.

d) foco epileptógeno - Fala-se em foco epileptógeno quando surgem no traçado figuras paroxísticas numa área bem delimitada. É, assim, possível uma clara localização de focos superficiais. Os mais profundos já são de localização mais difícil e podem ser projetados em ambos os hemisférios cerebrais, dando origem aos traçados de paroxismos bilaterais síncronos.

e) epilepsia generalizada - O "grande" e o "pequeno" mal dão origem a paroxismos elétricos bem definidos. $\mathrm{O}$ tipo de onda e sua frequiência diferem num e noutro caso. Contudo, essas descargas elétricas são generalizadas e descontínuas.

f) resultado negativo - Existem processos que não produzem alterações elétricas, de sorte que não podem ser estudados pelo E.e.g. Entretanto, é de importância muito maior o fato de que certas alterações são intermitentes. Assim, se o traçado fôr colhido num período juxtacrítico causará alteração útil do ponto de vista clínico, mas se fôr tomado num período intercrítico estará totalmente prejudicado. Em outros termos, êle será negativo apesar do processo mórbido ser efetivamente existente.

Para uma visão de conjunto, enumeramos a seguir as alterações mais importantes e mais freqüentes: 


\section{Principais anormalidades do E.E.G.}

I. Contínuas

A. Difusas $e$ Generalizadas

B. Localizadas

A. Generalizados

B. Localizados

II. Paroxísmos
1 - Lesōes inflamatórias

2 - Lesões degenerativas

3 - Meningites

4 - Encefalopatias

5 - Encefalites

6 - Traumatismos cerebrais

7 - Paralisia geral progressiva

8 - Esclerose em placas

9 - Psicoses orgânicas

10 - Psicoses funcionais

$$
\begin{aligned}
& 1 \text { - Tumores } \\
& 2 \text { - Abcessos } \\
& 3 \text { - Hematomas } \\
& 4 \text { - Cicatrizes } \\
& 5 \text { - Lesões vasculares } \\
& 6 \text { - Hemorragias } \\
& 7 \text { - Esclerose em placas } \\
& 8 \text { - Pós lototomia } \\
& 9 \text { - Sequela de difuza generalizada }
\end{aligned}
$$$$
10 \text { - Psicose funcional }
$$

1 - Estados convulsivos
a) freqüência rápida - Grande mal

b) freqüência lenta - Acessc psico-motor

c) freqüência alternada - Pequeno mal

2 - Por eletroconvulsoterapia

1 - Epilepsias focais
a) microgiria
b) cicatriz
c) atrofias
d) tumores
2 - Psicoses funcionais

\section{O valor do E.E.G..}

A eletrencefalografia ultrapassou os limites do laboratório para se converter num precioso elemento auxiliar de diagnóstico, tão valioso como o raio $\mathrm{X}$ ou a pneumencefalografia. Em alguns aspectos é insubstituível, particularmente no que diz respeito ao estudo das epilepsias, pois assim con- 
tribuiu muito para clarificar conceitos, esclarecer a fisiopatogenia, estabelecer dignósticos, avaliar prognósticos e hoje serve para se fazer uma seleção do método de tratamento. No tumor cerebral podemos observar sinais focais de localização muito antes que apareçam sinais oculares ou neurológicos. Não que êles tenham sido superados, mas a eletrencefalografia permite um diagnóstico mais precoce. Tôdas as estatísticas dos centros neurocirurgicos, onde se emprega o E.E.G., registram uma exatidão localizadora de 75 a $97 \%$. O E.E.G. não pretende sobrepujar nem anular os valores da ventriculografia, mas não pode ser desprezado no diagnóstico de localização de uma lesão tumoral. $\mathrm{Na}$ paralisia geral, as anomalias contínuas e generalizadas, aliadas a rítmos paroxísticos a sinais focais nas áreas frontais, constituem elemento bastante nítido de diagnóstico. Depois do tratamento, pode-se ter uma idéia dos efeitos que êste tenḥa produzido. $\mathrm{Na}$ conversão histérica os rítmos paroxísticos estarão ausentes, o que permitirá uma integração de outros sintomas psiquiátricos de suspeita chegar a uma orientação terapêutica correta.

Esquematicamente suas indicações são:

1. ${ }^{\circ}$ - Nas epilepsias - Serve para provar a existência da mesma, definir o tipo, analisar a origem e acompanhar a evolução terapêutica.

$2 .^{\circ}$ - Nas afecções cerebrais - permite diagnóstico e localização de lesão traumática, tumor, lesão vascular, atrofias, processos inflamatórios.

3..$^{\circ}$ - Na diferenciação entre epilepsia e histeria, bem como na explicação de certos tipos de comportamento.

Assim, o eletrencefalograma deve ser aceito sem reservas em tôdas as suas indicações, que, quando precisas, oferecerão resultados seguros de grande valia na clínica, tanto na fase diagnóstica como na fase terapêutica e também na avaliação prognóstica. 


\section{O E.E.G. em Criminologia.}

Os trabalhos que versam sôbre o eletrencefalograma de delinqüentes já são bastante numerosos. Alguns autores tem procurado fazer uma síntese dos achados eletrencefalográficos procedentes de variados centros de pesquisa, de sorte que encontramos publicações ricas em informes. Analisaremos algumas que nos parecem excelentes para uma visão panorâmica do assunto.

1 - No estudo das "personalidades psicopáticas", altamente freqüentes entre criminosos, foram estabelecidas algumas conclusões:

a) entre os agressivos observaram-se anomalias constitucionais inespecíficas, que se traduzem por excesso de rítmo teta bilateral e simétrico. Esses traçados usualmente mostram instabilidade a solicitações várias, tais como a hiperpnéia voluntária e a hipoglicemia. Outras vêzes pode-se observar a presença de ondas lentas, de freqüência delta acompanhada de discreta, porém evidente, alteração de consciência cronologicamente coincidente. Esse mesmo tipo de alteração no traçado é observável no exame de etilistas usuais.

b) processos ficais - Focos de ondas lentas, com 3 a 5 ciclos por segundo, de voltagem moderada, eventualmente se associando a ondas "sharp" de baixa voltagem uni ou bilateralmente situadas nas regiões temporais posteriores também foram descritas como achados importantes em delinqüentes.

c) material de estudo se mostrava bastante heterogêneo, pois os diagnósticos psiquiátricos eram variados: esquizofrenia, histeria, epilepsia. Havia um traço comum: agentes altamente agressivos.

II - A propósito ainda das "personalidades psicopáticas" verifica-se aqui maior incidência de anomalias do que entre os neuróticos e psicóticos, expressão feita das doenças órga- 
no-cerebrais. Segundo a revisão de Hill, a porcentagem de alterações patológicas apuradas por inúmeros autores, varia de 40 a $75 \%$. De outra parte, não foi possível estabelecer a existência de lesão específica, pelo que, houve quem negasse a possibilidade de correlação entre E.E.G. e diagnóstico de personalidade psicopática. Foram firmadas duas observações importantes.

a) ondas lentas - Excesso de rítmo teta ( 4 a 7 ciclos por segundo), bilateral e síncrono, com uma amplitude raramente maior do que o rítmo alfa, foi registrado por vários autores. A localização dessas ondas lentas é diferente segundo o autor considerado. Assim, enquanto alguns apontavam a região pós central, outros localizavam-nas na região frontal. Tentando resolver a controvérsia, foi obtido traçado com o emprêgo de electrodos dispostos transversalmente. $\mathrm{O}$ rítmo lento, então, se mostrou bilateral e síncrono nas regiões pós centrais, sugerindo que o foco se situa nas estruturas profundas da linha média.

b) entre psicopatas agressivos - que haviam apresentado amnésia, foi descrito foco de ondas de 3 a 5 ciclos por segundo, unilateral, de amplitude moderada na região temporal direita. cas, verificou-se:

c) comparando epiléticos e personalidades psicopáti-

1 - As crises paroxísticas são raras entre os psicopatas (2 a $3 \%$ ) e freqüentes entre os epiléticos (20 a 30\%)

2 - A atividade rápida é rara nos psicopatas (1,5 a $7,5 \%$ ) e freqüente entre os epiléticos (25\%)

3 - O E.E.G. das personalidades psicopáticas pode se comportar de modo semelhante ao dos epiléticos, quando ocorre alcalose respiratória ou hipoglicemia.

III - A partir da observação de alterações eletrencefalográficas encontradas em crianças com comportamento an- 
ti-social, levantou-se a hipótese de que modificações específicas poderiam ser encontradas nos traçados de delinqüentes. Entretanto, tal correlação parece não existir. Foi possível relacionar E.E.G. anormal, mas inespecífico, com delinqüência e mostrar que não há maior incidência de disritmia entre adolescentes criminosos do que entre os socialmente ajustados, bem como a possibilidade de delito ocorrer num período de metabolismo cerebral alterado.

IV - DELAY e VERDEAUX recentemente reafirmaram as conclusões dêste último, assim resumidas:

A - Rítmos teta - E altamente freqüente nos traçados de delinqüentes adultos. Chegam mesmo a estimar em $50 \%$ a freqüência dessa alteração em criminosos em geral. Afirmam que o significado varia:

$1 .^{\circ}$ - sofrimento cerebral - que pode ser reconhecido, ocorre com freqüência baixa (4 a 6 ciclos por segundo) e morfologia irritativa ou paroxística. É de localização particular (focal) e tem ainda maior valor diagnóstico se se acentuar durante a hiperpnéia. E preciso cautela na hipótese de se tratar de alcoolista ou traumatisado craneano.

$2 .^{\circ}$ - transtorno neurótico do comportamento - Observam-se rítmos teta entre impulsivos e portadores de defeito caracterológico. A freqüência é de 6 a 7 ciclos por segundo e morfologia semelhante à das ondas alfa.

$30^{\circ}$ - alteração funcional - E fácil de se excluir esta possibilidade, pois a alteração desaparece na repetição do traçado.

B - Rítmos de 4-5 ciclos ou baixa freqüência de alfa Esses rítmos foram observados em $40 \%$ de delinquientes. Essa apreciação merece ser examinada com cautela, pois essa alteração é igualmente encontrada entre alcoolistas crônicos e em $30 \%$ dos traumatisados craneanos.

C - Ondas lentas posteriores - Quando são observadas com caráter assimétrico, se relacionam à impulsividade. 
Em síntese - é de se esperar que entre delinqüentes o E.E.G. acuse ondas lentas, da faixa teta, ou ondas alfa nos limites inferiores, localizando-se quer nas regiões centrais, pós centrais ou posteriores. São essas as indicações feitas por variados autores, de várias escolas, como procuramos aquí dar um resumo.

\section{XI.}

Analisando 1.000 casos da Penitenciária do Estado, PRESA MARTINS obteve os seguintes resultados:

1) E.E.G. anormais 212

2) Tipos de anomalias

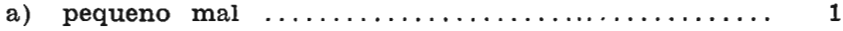

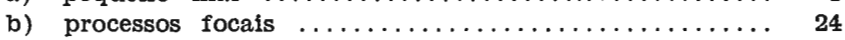

c) instabilidade diencefálica $\ldots \ldots \ldots \ldots \ldots \ldots \ldots \ldots \ldots 187$

TOTAL

212

As anomalias assim consideradas sobem a $21,2 \%$ o que concorda com resultados de outros autores aqui mencionados. Se, porém, levarmos em linha de conta que para muitos a diaritmia diencefálica pode correr por conta da hiperpnéia (DAVIS e WALLACE), teremos uma incidência de apenas $2,5 \%$ de anomalias.

\section{Conclusões.}

O exame panorâmico de técnica e dos resultados obtidos pela eletrencefalografia em Criminologia permite algumas conclusões:

1 Existem alterações importantes apuradas nos traçados de delinqüientes, especialmente dos impulsivos.

2 Embora as diferentes escolas não estejam totalmente de acôrdo, já foram estabelecidos padrões de traçado freqüientemente encontrado entre delinqüientes.

3 Quando o traçado é positivo (apura disritmia) seu valor é absoluto nas conclusões clínicas e nas implicações criminológicas. 
$4 \mathrm{O}$ exame eletrencefalográfico deve ser rotineiro nas observações criminológicas, em qualquer estágio penal.

5 As alterações observadas em 1.000 casos de São Paulo integram o texto deste trabalho.

\section{Notas Bibliográficas.}

1 BERger, H., apud ScotT, J. G. in Valor y limitaciones de la eletrencefalografia en la epilepsia - Documenta Gaigy.

2 Conrad, K. - Review of selection of epileptics, z. psych. Hyg. 10 167, 63, 152, 371, 1937. Apud Mayer-Gross.

3 Davis, H. - Wallace, W. Mcl. - Factors Affecting changes produced in Electroencephalogram by standardised Hyperventilation Arch Neurol Psychiatr. 47 606, 1942.

4 Delay, J.; VerdeaUX, G. - Electroencefalografia clínica - Torax - Masson - Barcelona, 1967.

5 Ellimgson, R. J. - Incidence of E.E.G. Abnormality among patients with Mental Disorders of Apparent Nonorganic Origin. 3 263-375 - 1954.

6 Gibis, F. A. - Davis, H. - LenNox, W. G. - The electroencephalogram in epilepsy and conditions of impsired consciousness. Arch. Neurol of Psychist. 34 1133, 1935.

7 Gibbs, F. A.; Bromberg, W.; BAgghi, B. K. - Eletrencephalographic study of criminals. Am. J. Psychiat. 102: 294-298, 1955.

8 HILL, D.; WatTerson, D. - Eletrencephalographic studies of psychopatic personalities. J. Neurol Psychiat. 9: 47, 1942.

9 Bilst, D. - Cerebral dysrhythimia: its significance in agressive behaviour. Proc. Roy. Soc. Med. 37 317, 1944.

10 HII,L, D. - E. E. G. in episodic psychotic behavior. Electroenceph clin. Neurophysiol. 4 429-442, 1952.

11 Lennox, W. G. - Mental defect in hereditary. Am. Psychol. 98733 e 737. 1942 .

12 Lennox, W. G.; Gibs, E. L.; Gibs, F. A. - The brain-wave pattern: an hereditary trait - J. Hered. $36235 \mathrm{seg} .371-377,1945$.

13 Levy, S.; Kennard, M. A. - E.E.G. Pattexn of Patients with Psychologic Disorders on various Ages. J. Nero \& Ment. Dis. 118: 416-428, 1953.

14 Lou, N. L. - Dawson, S. P. - Eletroencephulographic Findings in juvenlls delinquency. Pedriatrics 28 (3) 452-457, 19t:1. Excerp. Med. 15 (12)

15 Maxer Gross, W.; Slater, E.; Roth, N. - 1'siquiatria clínica - cap. IX - Ed, Psidos, 1958.

16 Presa Martins, T. - Comunicação pessoal.

17 REY, J. H.; POND, D. A.; Evans, L. C. - Cliılical end Electroencephalographic Studies of Temporal Lobs Function - Proc. R. Soc. Med. 42091 , 1949. 
18 Rosapepe, G. - Usefulness and limits of E.E.G. examination in criminology application of mental tests to forensic medicine Arm. neuropsychiat. psico and. 4(4) 467-474, 1957. Excerp. med. 12 (6).

19 Schwadg, E. D.; GeIger, S. - Behaviour disorders of the impulsive compulsive type with consistent abnormal E. E. G. findings. Electroencephal. clin. Neuro physiol. 7 473-474, 1955.

20 ScHWAdG, E.D.; GEIGER, S. - Abnormal electroencephalographic findings in severe behaviour disorders. Dis. Neur. System. 17 307-317, 1956.

21 Silverman, D. - Clinical and electroencephalographic studies on criminal psychopaths. Arch. Neurol. and Psychiat. 50 18, 1943.

22 SI"verman, D. - The electroencephalogram of criminals. Analysis of four hundred and eleven cases. Arch. Neurol. Psychiat. 52 38, 1944.

23 Verdeatu, G.; Verdeaux, G. - Cranial treuma and delinquency. The significance of the E. E. G. Ann. Med. Leg. 41 (3) 292-295, 1961. Excerp. Med. 15 (12).

24 Voshir, N.; Shimomoci, M.; TANI, M. - The electroencephalograma in juvenil delinquents. Folie Psychiat. Neurol. 85-91 1961. Excep. Med. 15(12).

25 WALTER, W. G. - The location of cerebral tumore by electroencephalography Lancet 2, 305, 1936. 